\title{
A BASIC EVALUATION FRAMEWORK FOR SPINAL CORD INJURY CARE SYSTEMS
}

\author{
By Byron B. Hamilton, Gustave J. Rath, Paul R. Meyer, Jr. and \\ JOEL S. ROSEN \\ Rehabilitation Institute of Chicago-Northwestern University, Chicago, Illinois, U.S.A.
}

SPINAL cord injury care centres and systems have been designated by the Department of Health, Education and Welfare in eleven locations throughout the United States. Two have been operational since the late I960s; nine more have been developed since 1972. One of the systems is centred in Chicago at the McGaw Medical Center of Northwestern University. It is formally known as the Midwest Regional Spinal Cord Injury Care System (MRSCICS); the two-hospital centre of the system consists of Northwestern Memorial Hospital, providing acute care, and the Rehabilitation Institute of Chicago, providing comprehensive rehabilitation services.

It is generally agreed by the spinal cord injury care centres that a major purpose is to demonstrate in an objective manner the effectiveness and cost of systematic care of spinal cord-injured man. The outcome effectiveness and cost of these systems of comprehensive care are important to casualty and health insurers, federal and state government agencies, the staff and management delivering care services; but most importantly to the person with spinal cord injury and his or her family. An outcome evaluation strategy has been developed and initially implemented by the Midwest Regional Spinal Cord Injury Care System; it is based on a problem-solving set of objectives. The problem-objectives confronting all centres may be summarised as follows (see fig. I).

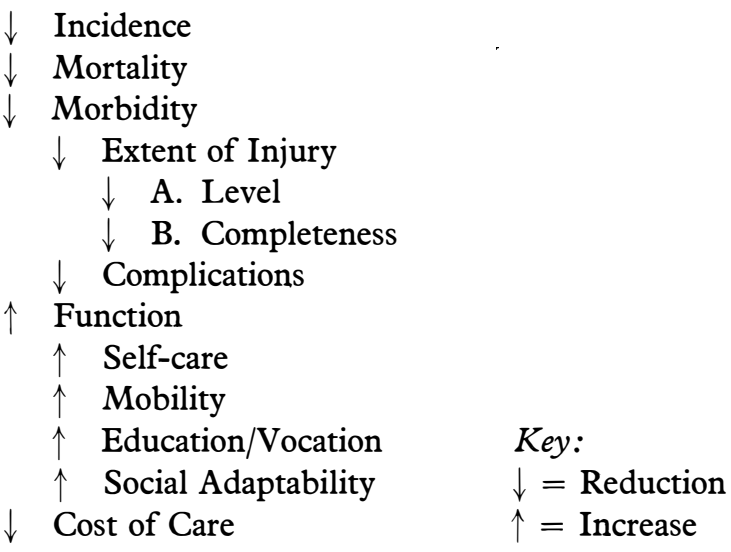

FIG. I

Spinal cord injury care system objectives. 
TABLE I

Spinal cord injury care system

\author{
Prevention \\ Evacuation \\ Acute care \\ Rehabilitation (early) \\ Follow-along (life-long)
}

How can the incidence of spinal cord injury be reduced? When such an injury has occurred how can the mortality and morbidity be reduced? How can the extent of injury and complications be reduced? How can function in self-care, mobility, school and work, or in social adaptibility be increased ? Finally, how can the tremendous cost of care and maintenance for spinal cord injury be reduced? These are the problems; the objectives are to solve them.

In order to better solve these problems, spinal cord injury care systems have been developed by each of the designated centres. They tend to conform to the five major sub-systems shown in Table I.

It is clear that the objective of the Prevention sub-system is to reduce incidence of accidents which cause spinal cord injury, and to prevent mortality and morbidity, when such accidents do occur. The Evacuation sub-system objective is to reduce mortality and morbidity by transporting the spinal cord-injured patient to acute care as early, and with as little progression of the injury en route, as possible. This may include administration at accident site of drugs to prevent auto-inflammatory damage of the contused spinal cord.

The Acute Care sub-system is directed at reducing mortality and morbidity, by stabilising failing organ systems, and preserving as much function as possible. The early Rehabilitation sub-system objectives are to prevent complications, increase and maintain function in the areas of self-care, mobility, education/ vocation and social adaptation. The Follow-Along sub-system objective is essentially one of preventive maintenance; to maintain function and prevent complications as long as possible. The total spinal cord injury care system composed of all of the sub-systems has the implicit objective of maintaining a favourable effectiveness/cost ratio in managing the entire problem-solving effort. That is, the system, compared to alternative methods, should solve the above problems most adequately with the least cost to society.

In order to demonstrate that the spinal cord injury care system concept is, or is not, 'cost/effective', the evaluation plan should be geared to document how well the problems have been solved (that is, the system output); it must also indicate what solutions were actually used (that is, the system process). Let us look at a basic processing system to see what this 'output' and 'process' business is all about (see fig. 2).

If one needs to make milk one gets a cow and some grass. The cow provides the Process; that is, the machinery to convert grass (the Input in the system) into milk (the Output). The cow is very clever because in eating the grass she has also found a source of energy (the Effort or Cost) needed to run the process machinery. Likewise (see fig. 3), if your objective is to reduce spinal cord injury incidence, mortality and morbidity, and to increase function, you may develop a process consisting of Prevention, Evacuation, Acute Care, Rehabilitation and Follow-Along; then find hard working people and money to provide the effort to make the process go. The input into the system is the pre-spinal cord injured 


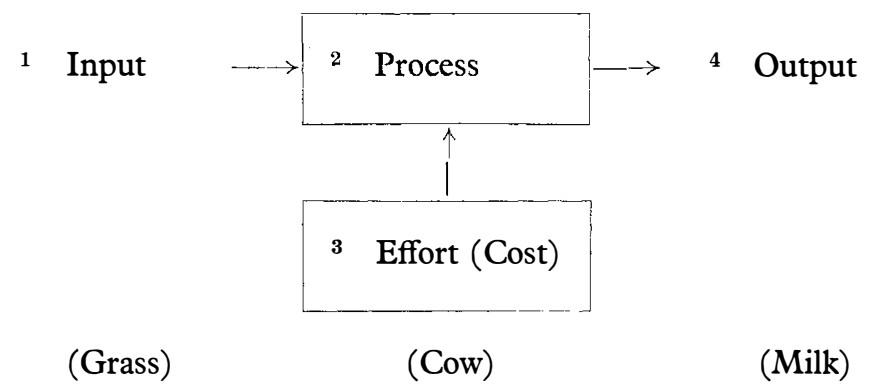

FIG. 2

A basic processing system.

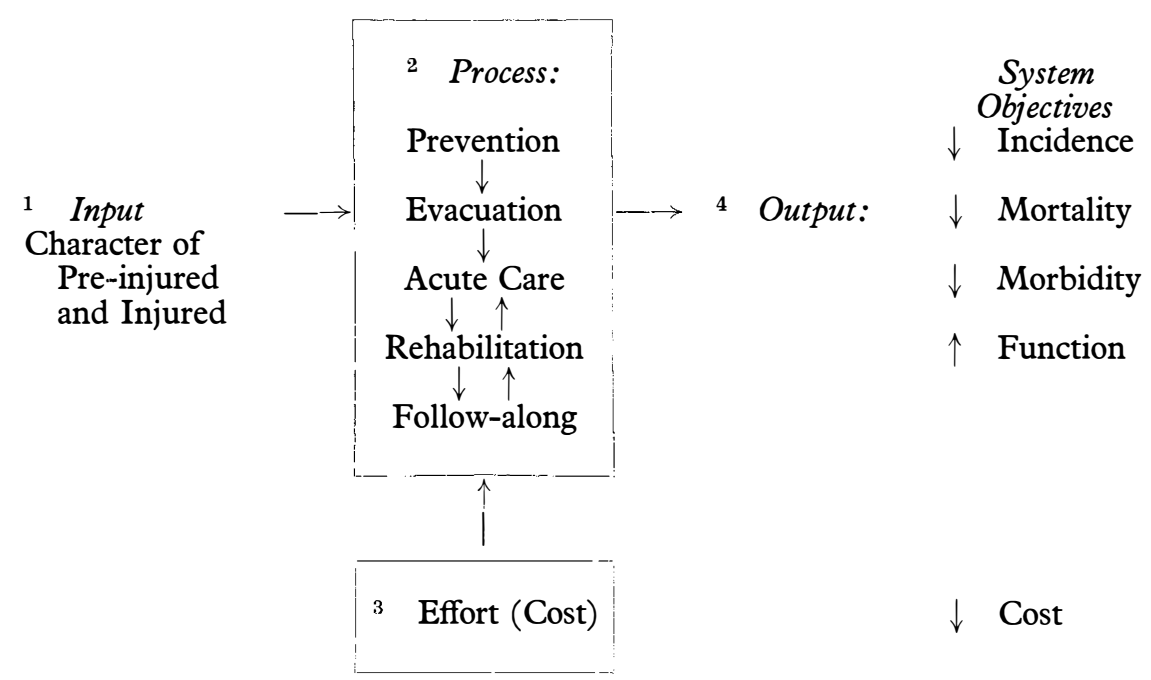

Fig. 3

Basic processing system applied to spinal cord injury.

or spinal cord injured. The output is people with preserved human resources (fig. 3).

If all this is clear you should now understand what 'input', 'output', 'process' and 'effort' mean. We have just carried out a simple system analysis (actually, two simple system analyses if you include the cow). If we are going to evaluate spinal cord injury care systems we will need information about each of these system elements.

So much for anatomy of 'systems' in general and spinal cord injury care systems in particular. Let us look now at some of the details of the system evaluation framework itself and what is actually to be measured.

The adequacy of performance of any process or system should be determined in terms of achievement of set goals or objectives. However, there is some difficulty in establishing absolute performance objectives in the case of health care delivery systems, because the absolutes cannot be achieved (for example, all spinal cord 


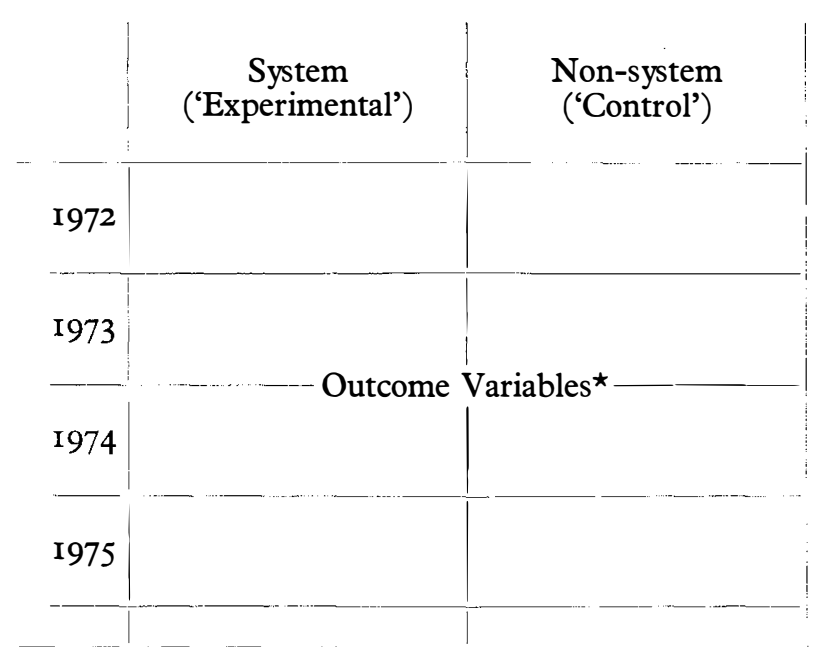

* The outcome variables are incidence, mortality, morbidity, function, cost, and their sub-variables.

FIG. 4

System outcome evaluation.

injuries cannot be prevented). Likewise, relative goals are difficult to establish because, short of total prevention, how much is 'adequate'? 75 per cent? 25 per cent? We are left with a system that must be evaluated in terms of what it can achieve. There are several ways this can be done: we can measure performance over time and quantitate change; we can compare the measured performance of a 'system' with a 'non-system'; we can compare one system with another system.

Figure 4 indicates what an evaluation matrix measuring outcome performance of a 'system' versus a 'non-system', over time, would look like. Note that this scheme can be considered akin to an experimental research design in which the 'system' method is equivalent to the experimental method and the 'non-system' is equivalent to the experimental 'control'.

An important implication of any system outcome evaluation is that the system process is in fact responsible for or causing the outcome, just as the independent variables in a scientific experiment are responsible for or causing the behaviour of the dependent variables. If and when such a cause-effect relationship exists and can be demonstrated in a health service delivery system then such a system has credibility and utility. It is anticipated that the above evaluation scheme will provide for such credibility.

The discussion to this point has dealt primarily with outcome and cost evaluation. A few words must be said about documenting or characterising the other system components, namely 'process' and 'input', because they can have a profound effect on outcome and cost. For example, a system handling more quadraplegics than paraplegics or more complete than incomplete lesions will have a different outcome than one with more 'paras' and 'incompletes'; so, consideration of these and other input characteristics will be important in the evaluation scheme. Further, for purposes of improvement of system process and for system propagation (that is, education and training), it will be important to document the programme, procedures and devices being used in that process. It is not within the 
scope of this paper to outline the documentation requirements for system input and process; suffice it to say, they must be included in the evaluation plan.

Finally, let us look at some actual data to which the basic outcome evaluation framework has been applied. From this the utility of the framework will be more apparent. Table II summarises data available now on some outcome and cost variables for the Midwest Regional Spinal Cord Injury Care System. Caution: this data is not complete for any given variable and inference about how this system is actually doing is not warranted at this time. The data is presented to illustrate the evaluation framework.

Notice that in Table II the system outcome and cost variables are listed down the left-hand margin. The annual periods 1972 through 1974 are captioned across the top; for each year, data on 'system', 'non-system' and 'total' patients is indicated (see key for definitions).

The following system evaluation observations may be made:

I. Incidence: MRSCICS has 'captured' I9 per cent (9I) of the estimated 480 new spinal cord injuries in the catchment area in 1974; this is an increase of 12 per cent over 1973 and 32 per cent since the system began.

2. Mortality: Three per cent of known system/non-system patients have died during $1974 ; 4$ per cent since the system began. Regional mortality rate is unknown. Non-system patients may have an apparent advantage over system.

3. Morbidity: The extent of spinal cord injury in terms of level of new injury has remained about the same (45 per cent quadriplegic) as in 1973 (48 per cent), and higher than when the system began in 1972 (37 per cent). The number of complete lesions has unexplainably and significantly decreased in 1974 ( 52 per cent) compared to 1973 (70 per cent) and 1972 (66 per cent). There is not an apparent difference between system and non-system patient extent of injury.

The complication rate for skin pressure ulcers in matched pairs of patients has decreased from 50 per cent in 1972 to 42 per cent in 1973 and $4 \mathrm{I}$ per cent in 1974. System patients have an average of 67 per cent fewer ulcers than non-system in 1973 and 1974 in the first calendar year of injury. The number of system patients with unplanned readmissions is slightly greater than non-system.

4. Life Function: By the third year following injury 52 per cent of patients were gainfully placed, by the second 48 per cent and in the first year I 8 per cent. This pattern implies a long-term placement process and need for vocational follow-along. System patients have a slight placement advantage with the small sample available.

5. Cost: Average cost of first hospitalisation for matched pairs of spinal cord injured patients in 1974 was $\$ 19,400$; this is a decrease of $\$ 4300$ (I8 per cent) since 1973 and $\$ 7900$ (29 per cent) since 1972. System patients appear to have a significant cost savings advantage over non-system, averaging $\$ 5967$ (22 per cent) per patient for first hospitalisation over the first 30 months of MRSCICS operation. When extrapolated ${ }^{1}$ to United States national spinal cord injury incidence this represents a potential annual savings of $\$ 30$ million for the first hospitalisation alone.

1 Based on an incidence rate of 24 spinal cord injuries per million population, the U.S. has about 5000 new spinal cord injuries per year. At a cost savings of $\$ 5967$ per patient the national savings would be $\$ 30$ million annually. 


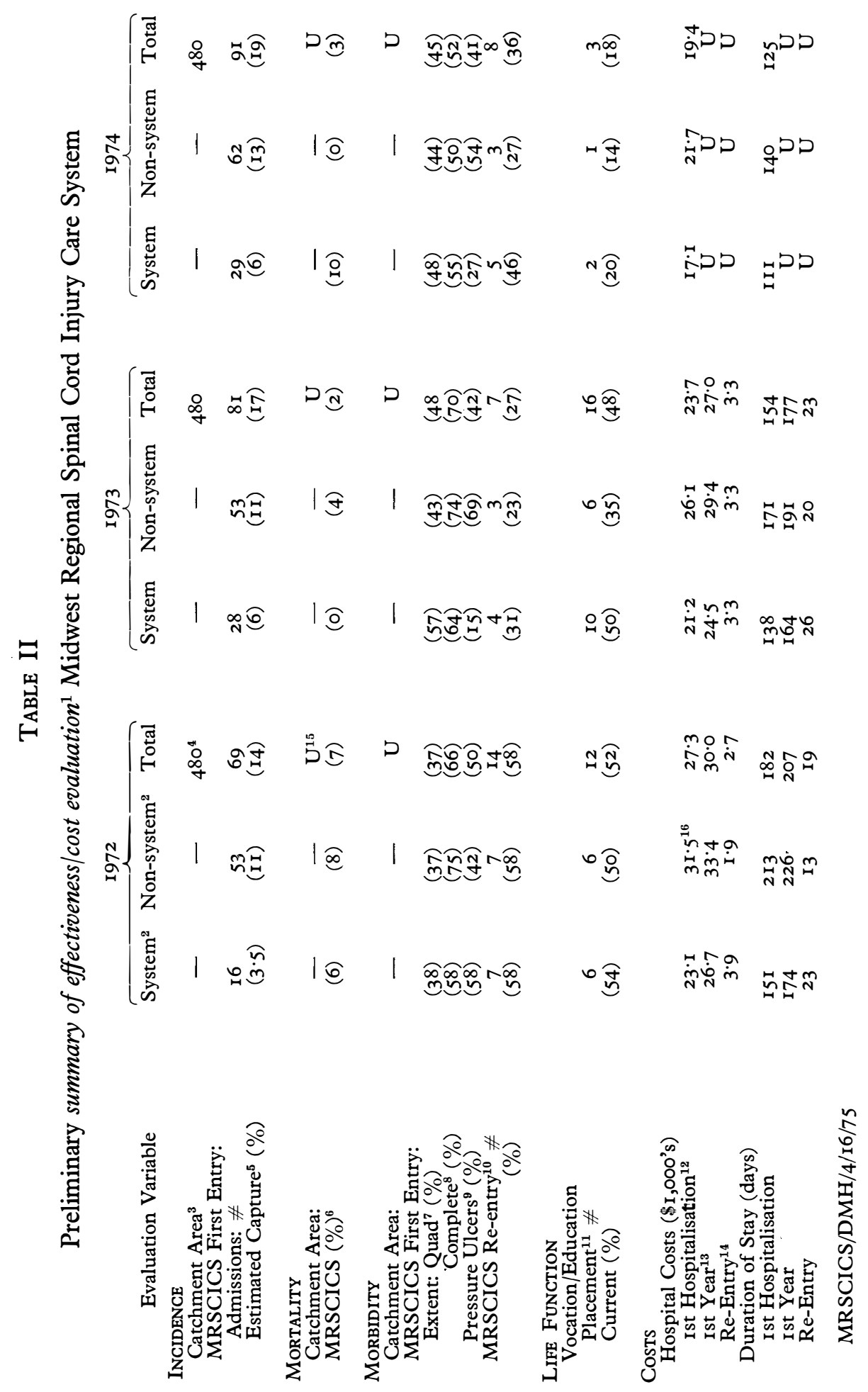




\section{Table II: KEY}

I. Caution is recommended in interpreting this preliminary data; some data sets are incomplete.

2. 'System patients' are those admitted less than $\mathbf{7 2}$ hours after injury; 'non-system', greater than 72 hours.

3. Catchment area: 200 mile radius around Chicago, plus all of Illinois.

4. Estimated incidence of new spinal cord injuries is 24 per million population per year. MRSCICS catchment population is 20 million. Estimated MRSCICS incidence therefore is 480 new injuries per year.

5. Estimated 'capture' is percentage of catchment area injuries admitted to MRSCICS that year.

6. MRSCICS mortality rate is reported percentage of deaths in a given category.

7. Percent of patients with quadriplegia injured that year.

8. 'Complete' means percentage of patients injured that year with no neural transmission below the level of the spinal cord injury.

9. 'Pressure ulcer' refers to percentage of patients with the complication of skin pressure ulcer (matched pairs).

IO. Number/(percentage) of system/non-system paired patients readmitted (unplanned) to a MRSCICS hospital.

I I. 'Placement' refers to placement in gainful activity (work, school, vocational training, home-making sheltered workshop) (matched pairs).

I2. 'Ist hospitalisation' refers to continuous first acute care and rehabilitation hospitalisation following injury until first definitive discharge to community (matched pairs).

I3. 'Ist year' means first I 2 months following injury (matched pairs).

14. 'Re-entry' means readmission to acute care or rehabilitation hospital after the first year following injury (matched pairs).

I5. ' $U$ ' indicates information is unavailable at time of reporting.

I6. The non-system acute care hospital costs are not directly available but are estimated on the basis of average daily NMH costs for system patients times the number of days prior to MRSCICS entry.

Similarly, the duration of first hospitalisation has decreased from 182 to 125 days (an average of 57 days or 31 per cent) since 1972. System patients stay an average of $4 \mathrm{I}$ days (24 per cent) less than non-system.

From these observations it could be determined that this system output over time is changing in a number of its variables toward the desired outcome. Further, 'System' patients appear to have better outcome characteristics than 'non-system'. Completion of the evaluation framework, including scaling and weighting of variables and putting them in a 'cost-effectiveness' format, must await more data and time. It should be pointed out that more variables and more rigour can be applied to this evaluation framework.

It is expected that multiple centres will join in the collection of data which will demonstrate the effectiveness and cost of systematic care of the spinal cord injured in the United States. The evaluation framework presented here is submitted as a basic plan for such a demonstration, as well as a management tool with which a given system of care can determine its own effectiveness.

\section{SUMMARY}

Regional spinal cord injury care systems have recently been initiated in the United States. A basic strategy for evaluating effectiveness and cost of care in these systems has been developed and preliminary results from one of the regional systems indicates the utility of the evaluation plan and effectiveness/cost savings of the system. 


\section{RÉSUMÉ}

Des systèmes régionaux de soins des lésions de la moelle épinière ont été récemment mis au point aux Etats-Unis. On a élaboré une stratégie de base pour l'évaluation de l'efficacité et du coût des soins donnés dans le cadre de ces systèmes et les premiers résultats enregistrés dans l'un de ces systèmes régionaux font apparaître l'utilité du plan d'évaluation et l'économie du système quant au rapport coût/efficacité.

\section{ZUSAMMENFASSUNG}

Regionale Systeme für die Fürsorge von Rückenmarksverletzten sind vor kurzem in USA eingeführt worden. Eine grundlegende Strategie für die Berechnung der Leistungsfähigkeit und Kosten der Fürsorge dieser Systeme wurde entwickelt und die ersten Resultate eines der regionalen Systeme weist auf die Nützlichkeit dieser System hin. 